\title{
Olive Ridley Sea Turtle Hatching Success as a Function of Microbial Abundance and the Microenvironment of In Situ Nest Sand at Ostional, Costa Rica
}

\author{
Vanessa S. Bézy, ${ }^{1}$ Roldán A. Valverde, ${ }^{2}$ and Craig J. Plante ${ }^{1}$ \\ ${ }^{1}$ Department of Biology, College of Charleston, 66 George Street, Charleston, SC 29424, USA \\ ${ }^{2}$ Department of Biological Sciences, Southeastern Louisiana University, SLU Box 10736, Hammond, LA 70402, USA \\ Correspondence should be addressed to Vanessa S. Bézy; vanessa.bezy@gmail.com
}

Received 11 August 2014; Revised 18 November 2014; Accepted 21 November 2014; Published 22 December 2014

Academic Editor: Horst Felbeck

Copyright (c) 2014 Vanessa S. Bézy et al. This is an open access article distributed under the Creative Commons Attribution License, which permits unrestricted use, distribution, and reproduction in any medium, provided the original work is properly cited.

\begin{abstract}
Sea turtle hatching success at mass nesting beaches is typically lower than at solitary nesting beaches, presumably due in part to high rates of microbial metabolism resulting from the large input of organic matter from turtle eggs. Therefore, we tested the hypothesis that hatching success varies across areas of the beach in conjunction with differences in the physical nest environment and microbial abundance of in situ olive ridley sea turtle nests at Ostional, Costa Rica. We marked natural nests in high-density, lowdensity, and tidal-wash nesting areas of the beach and monitored clutch $\mathrm{pO}_{2}$ and temperature throughout the incubation period. We quantified hatching success and collected samples of nest sand during nest excavations. We quantified microbial abundance (bacteria and fungi) with a quantitative polymerase chain reaction (qPCR) analysis. Hatching success was lower in nests with lower $\mathrm{pO}_{2}$, higher temperatures, higher organic matter content, and higher microbial abundance. Our results suggest that the lower oxygen within the nest environment is likely a result of the high microbial abundance and rates of decomposition in the nest sand and that these factors, along with increased temperature of clutches in the high-density nesting area, are collectively responsible for the low hatching success at Ostional.
\end{abstract}

\section{Introduction}

The olive ridley sea turtle (Lepidochelys olivacea) is listed by the IUCN as a vulnerable species. The major threats to this species include fisheries bycatch, habitat degradation, and the unsustainable harvest of eggs [1]. This species is characterized by a nesting behavioral polymorphism, with some females nesting solitarily and others nesting en masse. Mass nesting events at Ostional, Costa Rica are some of the largest in the world, with events (or arribadas) estimated at up to approximately 500,000 nesting females [2]. Yearly arribada abundance at Ostional has exhibited a decrease over the past 15 years, which has been attributed in part to the particularly low hatching success at this beach $(8 \%$; $[2,3])$. While nest density can adversely affect hatching success (due to competition between developing embryos for physiological requirements), the mean nest density at
Ostional is not high enough to reduce hatching success to the drastically low levels observed $[4,5]$.

Rather, several studies have suggested that embryo mortality is associated with the high microbial load resulting from the decomposition of eggs broken by subsequent nesting turtles during these high-density arribada events $[4,6,7]$. For example, a previous study at an arribada beach observed higher temperature and partial pressure of carbon dioxide $\left(\mathrm{pCO}_{2}\right)$, and lower partial pressure of oxygen $\left(\mathrm{pO}_{2}\right)$, in egg clutches incubated in situ versus a hatchery [8]. This same study also reported increased hatching success in the cleaner (tidal washed and sieved) hatchery sand in comparison to natural beach sand. Therefore, microbial load and organic matter could presumably be responsible for these differences and may influence hatching success. In fact, nutrient loads and bacterial abundance in the sand at mass nesting beaches 
are much higher than at neighboring beaches $[9,10]$. Furthermore, Cornelius et al. [6] suggested that observed increases in hatching success in nests below the high tide line may be due to natural tidal washing, which could remove microbes that are intolerant to salt water. Another study at arribada beaches found that while bacterial phylotype richness and diversity increased with increasing nest density in the high and middle zones of the beach, this was not true in the low zone of the beach, perhaps due to the less stable osmotic environment caused by the tides [11].

Bacteria and fungi have been cultured and isolated from nest sand and failed eggs as well as from the cloacal fluid of nesting females $[10,12,13]$. However, the literature on the infection of sea turtle eggs by microbes is controversial. Microbial infection was traditionally thought to be opportunistic and limited laboratory studies found no significant effect of the presence of bacteria or fungi on the hatchling production of olive ridley sea turtle eggs $[10,12,14]$. More recent studies on the Fusarium solani species complex have identified several fungal pathogens to sea turtle eggs $[15,16]$. However, eggs infected with $F$. solani can be asymptomatic [15] and other studies challenge this causality [17, 18]. These studies reflect the difficulty in directly linking embryo mortality to the presence of microbes, in part due to limitations in conducting research on protected species as well as the high occurrence of total nest failure in such studies $[14,19]$.

While the negative effect of higher microbial densities on hatching success at Ostional has long been presumed, no previous research has ever directly quantified microbial abundance or the associated conditions of the nest environment with respect to hatching success in natural nests. Because sea turtle embryo mortality is likely linked to many factors, it is necessary to evaluate the entire nest environment in order to fully understand the interactions between a clutch of eggs and the microecosystem that comprises a sea turtle nest $[13,20]$.

The aim of this study was to describe the natural conditions of the sea turtle nest environment at Ostional in order to identify factors that may be adversely impacting sea turtle embryonic development. We tested the hypothesis that hatching success varies across the beach in association with differences in the nest environment and microbial abundance. We predicted that higher hatching success would occur in beach areas exposed to tidal washing and that an inverse relationship exists between microbial abundance and hatching success. To accomplish this, we monitored nest conditions (i.e., temperature, oxygen, and organic matter content) and hatching success in natural nests located in different areas of the beach and quantified the microbial abundance in nest sand.

\section{Methodology}

2.1. Study Site. The Ostional National Wildlife Refuge (ONWR) is located on the Pacific coast of the Nicoya Peninsula in Costa Rica $\left(9.996471^{\circ} \mathrm{N}, 85.697800^{\circ} \mathrm{W}\right)$. Within ONWR, the Nosara and Ostional beaches make up approximately $7 \mathrm{~km}$ of beach with variable width. This study was conducted at Ostional beach during the rainy season (May through November) of 2012, when arribadas are typically more abundant. All study nests were laid during the same night of the arribada that occurred during the last quarter moon of August 2012 (hereinafter called the sample arrib$a d a$ ). This ensured that all nests incubated at the same time and helped standardize any uncontrollable variables that could affect hatching success, such as ambient temperature and rainfall.

We compared the microbial abundance in relation to hatching success in natural (in situ) nests located in a tidalwash area, a high-density nesting area where arribadas tend to concentrate, and a low-density nesting area. The tidal-wash area of the beach was located within 25 meters of a lagoon and in the tidal-wash zone, where the tide is known to wash over the berm and cause sand turnover. The high-density nesting area was located at the main nesting beach, where the sample arribada was recorded to have the highest density of nesting females. The low-density nesting area was located where the sample arribada was recorded to have the lowest density of nesting females. Nest densities for the sample arribada were determined by the strip-transect-in-time method and confirmed with quadrat sampling at the time of excavation $[5,21]$.

We randomly selected five nests above the average high tide line in the tidal-wash, high-nest-density, and low-nestdensity beach areas described above. Eggs were counted during oviposition to determine the total clutch count. A datalogger and oxygen tubing were placed within the center of the nest chamber, after approximately 50 eggs were laid. A 5 -sided $50 \times 50 \times 15 \mathrm{~cm}$ wire mesh cage with a wooden frame was placed over the nest and buried entirely below the surface of the sand to prevent predation and excavation by subsequently nesting females. This cage was pulled above the surface of the sand on day 40 of incubation to allow hatchlings to emerge to the surface unobstructed. Nests were then monitored three times daily (sunrise, sunset, and midnight) for signs of hatching in order to count and release hatchlings as soon as possible.

2.2. Nest $\mathrm{pO}_{2}$. Nest $\mathrm{pO}_{2}$ was monitored by placing an air stone fitted with the tip of $60 \mathrm{~cm}$ nylon tubing into the center of the egg mass that ran from inside of the nest chamber to the top layer of sand where a shut-off valve impeded any additional gas exchange $[4,8,22]$. The $\mathrm{pO}_{2}$ within the egg clutch was measured using a flow-through oxygen sensor (S108 Oxygen Analyzer, Qubit Systems) that was calibrated prior to the field season using nitrogen and prior to each set of samples using atmospheric air. Dead air space (approximately $10 \mathrm{~mL}$ ) was drawn from within the tubing and expelled prior to sampling to ensure the air sample was from within the nest cavity. Air samples (approximately $60 \mathrm{~mL}$ ) were drawn using an airtight syringe and analyzed within $1 \mathrm{~h}$ of collection. Samples were slowly injected through an air pump, flow meter, and desiccant column and through the $\mathrm{O}_{2}$ sensor at a flow rate of approximately $50 \mathrm{~mL} \mathrm{~min}^{-1}$. Air samples were analyzed every 5 days for the first 30 days of incubation and every 4 days through the end of the incubation period. Gas percentages were converted to partial pressures using ambient barometric pressure. 
2.3. Nest Temperature. Nest temperature was monitored using $\mathrm{HOBO}$ pendant temperature dataloggers (Onset Computer Corporation) placed in the center of each clutch and programmed to record temperature at $3 \mathrm{~h}$ intervals starting at midnight on the night of oviposition through hatchling emergence. Mean daily nest temperatures were used to compare nest temperatures across the different areas of the beach.

2.4. Nest Excavations. Single-use sterile gloves were worn for all excavations and changed before contact with different nests. Nests were exhumed three days after the last observed hatchling emergence to quantify hatching success [23].

2.5. Sand Collection and Characterization. A sample of sand was collected directly into sterile collection tubes from the center of the nest chamber during the excavation of the nest at the end of the incubation period. Samples were placed on ice immediately after collection and then either frozen $\left(-20^{\circ} \mathrm{C}\right)$ or preserved in formalin ( $2 \%$ formaldehyde) within $6 \mathrm{~h}$ of collection and until analysis. The organic matter analysis consisted of a loss-on-ignition method, with the organic matter content being the loss of mass after dry combustion. The sample was transferred to a porcelain container and desiccated in a drying oven $\left(24 \mathrm{~h}\right.$ at $\left.100^{\circ} \mathrm{C}\right)$ before combustion $\left(6 \mathrm{~h}\right.$ at $\left.500^{\circ} \mathrm{C}\right)$. Prior to combustion, samples of dried sand were fractionated with a set of sieves $(0.063,0.075,0.15,0.25$, 0.45 , and $0.85 \mathrm{~mm}$ ) to determine the particle-size distribution by mass. Mean grain size $(\phi)$, sorting $\left(\sigma_{\phi}\right)$, and skewness $\left(\mathrm{Sk}_{\phi}\right)$ were calculated using the logarithmic mathematical "method of moments" in GRADISTAT [24, 25].

2.6. Microbial Abundance. Samples preserved in formalin were used for microscopy counts as a secondary method of quantifying bacterial abundance. These samples were centrifuged for $10 \mathrm{~min}$ at $16,000 \mathrm{~g}$ in a microcentrifuge before carefully removing excess formalin. The sand was then diluted (approximately 1:2) with sterile water and sonicated on ice for $20 \mathrm{~s}$ at $30 \mathrm{~W}$ (Sonifier S-250A, Branson). The resulting supernatant fluid was stained for approximately 5 minutes with a 1:10 dilution of $1 \mathrm{x}$ SybrGold and sterile water. Microscopy counts were performed at 1000x magnification on an epifluorescence microscope (Optiphot-2, Nikon) by counting 10 fields per slide. The number of cells $\mathrm{g}^{-1}$ of sand was then calculated based on the original weight of sand, volume of diluent and supernatant, and the average number of cells field ${ }^{-1}$ using the number of fields per slide at $1000 \mathrm{x}$ $\left(4.79 \times 10^{4}\right)$ and correction factor for the addition of formalin $(\times 1.16)$.

We used a quantitative real-time polymerase chain reaction (qPCR) analysis to determine the abundance of bacteria based on the number of 16S rRNA gene copies $\mathrm{g}^{-1}$ nest sand and the abundance of fungi based on the number of $18 \mathrm{~S}$ rRNA gene copies $\mathrm{g}^{-1}$ nest sand. While the resulting quantification of gene copies from a qPCR analysis cannot be directly transformed into the number of cells (given that copy number can vary greatly between species), this can be used as a proxy for overall abundance of microbial communities [2628].
2.7. DNA Extraction. Each sample of sand was thawed and homogenized by vortexing before collecting a $1 \mathrm{~g}$ subsample for DNA extraction. DNA was extracted from all samples of sand using an EZNA Soil DNA kit (Omega Biotek) with the following modifications to the protocol to increase DNA yields. Samples were subjected to $5 \mathrm{~min}$ at approximately 2,000 oscillations $\mathrm{min}^{-1}$ in a bead beater (Mini Beadbeater-8, Biospec Products) and three freeze-thaw cycles $\left(-20^{\circ} \mathrm{C}\right.$ and $70^{\circ} \mathrm{C}$ for $30 \mathrm{~min}$ each) during the lysis step. Additionally, in the final step of extraction only $50 \mu \mathrm{L}$ of elution buffer was used, which was reapplied to the column in the second elution step. DNA samples were diluted in order to reduce inhibition and optimize efficiency and $\mathrm{Ct}$ values to within the range of the standard curve.

2.8. qPCR Analysis. Absolute qPCR was run using an iCycler iQ Real-Time PCR Detection System (Bio-Rad Laboratories, Inc.) on a 96-well plate. Results were analyzed using iQ5 software (Bio-Rad Laboratories, Inc.). The universal bacterial primers 926F ( $5^{\prime}$-AAA CTC AAA KGA ATT GAC GG-3') and 1062R ( $5^{\prime}$-CTC ACR RCA CGA GCT GAC-3 $\left.{ }^{\prime}\right)$ that target the 16S rRNA gene were used based on a previous study by de Gregoris et al. [29]. Each $10 \mu \mathrm{L}$ reaction contained the following: $5 \mu \mathrm{L}$ of ABsolute qPCR Master Mix (ABgene), $0.1 \mu \mathrm{L}$ bovine serum albumin $\left(10 \mu \mathrm{g} \mu \mathrm{L}^{-1}\right.$; Thermo Scientific), $0.3 \mu \mathrm{L}$ of each primer $(10 \mu \mathrm{M}, 300 \mathrm{nM}$ final concentration; Integrated DNA Technologies), $3.9 \mu \mathrm{L} \mathrm{H}_{2} \mathrm{O}$, and $0.4 \mu \mathrm{L}$ template DNA. PCR conditions were $15 \mathrm{~min}$ at $95^{\circ} \mathrm{C}$, followed by 40 cycles of $95^{\circ} \mathrm{C}$ for $15 \mathrm{~s}, 15 \mathrm{~s}$ at the annealing temperature of $57^{\circ} \mathrm{C}$, and $72^{\circ} \mathrm{C}$ for $20 \mathrm{~s}$.

The universal fungal primers FR1 $\left(5^{\prime}\right.$-AICCATTCAATCGGTAIT- $\left.{ }^{\prime}\right)$ and FF390 ( $5^{\prime}$-CGATAACGAACGAGACCT$3^{\prime}$ ) that target the 18S rRNA gene were used based on previous studies $[26,30]$. Each $10 \mu \mathrm{L}$ reaction contained the following: $5 \mu \mathrm{L}$ of ABsolute qPCR Master Mix (ABgene), $0.1 \mu \mathrm{L}$ bovine serum albumin $\left(10 \mu \mathrm{g} \mu \mathrm{L}^{-1}\right.$; Thermo Scientific), $0.1 \mu \mathrm{L}$ of each primer $(10 \mu \mathrm{M}, 100 \mathrm{nM}$ final concentration; Integrated DNA Technologies), $4.3 \mu \mathrm{L} \mathrm{H}_{2} \mathrm{O}$, and $0.4 \mu \mathrm{L}$ template DNA. PCR conditions were $15 \mathrm{~min}$ at $95^{\circ} \mathrm{C}$, followed by 40 cycles of $95^{\circ} \mathrm{C}$ for $15 \mathrm{~s}, 30 \mathrm{~s}$ at the annealing temperature of $50^{\circ} \mathrm{C}$, and $72^{\circ} \mathrm{C}$ for $1 \mathrm{~min}$.

2.9. $q P C R$ Standards. External, fixed standards were created by amplifying and quantifying bacterial and fungal DNA using primer sets that targeted the full $16 \mathrm{~S} / 18 \mathrm{~S}$ rRNA sequence. Template DNA extractions for bacterial and fungal standards were kindly provided from cultures of Bacillus pumilus (W. Hook, Grice Marine Laboratory, College of Charleston, Charleston, SC) and Phytophthora capsici (J. Ikerd, U.S. Vegetable Laboratory, USDA, ARS, Charleston, SC), respectively. For bacteria, the universal primers $8 \mathrm{~F}\left(5^{\prime}\right.$-AGAGTTTGATCCTGGCTCAG- $\left.3^{\prime}\right)$ and 1492R $\left(5^{\prime}\right.$-GGTTACCTTGTTACGACTT- $\left.3^{\prime}\right)$ were used with the following PCR conditions: $3 \mathrm{~min}$ at $95^{\circ} \mathrm{C}$, followed by 30 cycles of $95^{\circ} \mathrm{C}$ for $1 \mathrm{~min}, 1 \mathrm{~min}$ at the annealing temperature of $45^{\circ} \mathrm{C}$, and $72^{\circ} \mathrm{C}$ for $1.5 \mathrm{~min}$, with a final elongation step of $4 \mathrm{~min}$ at $72^{\circ} \mathrm{C}[31,32]$. For fungi, the universal primers NS1 $\left(5^{\prime}\right.$-GTAGTCATATGCTTGTCTC- $\left.3^{\prime}\right)$ and NS8 $\left(5^{\prime}\right.$-TCCGCAGGTTCACCTACGGA- $\left.{ }^{\prime}\right)$ were used with the 
following PCR conditions: $4 \mathrm{~min}$ at $95^{\circ} \mathrm{C}$, followed by 30 cycles of $95^{\circ} \mathrm{C}$ for $1 \mathrm{~min}, 2 \mathrm{~min}$ at the annealing temperature of $55^{\circ} \mathrm{C}$, and $72^{\circ} \mathrm{C}$ for $1.5 \mathrm{~min}$, with a final elongation step of $10 \mathrm{~min}$ at $72^{\circ} \mathrm{C}[33,34]$. Each $25 \mu \mathrm{L}$ PCR reaction contained the following: $5 \mu \mathrm{L}$ of buffer ( $5 x$ colorless GoTaq Flexi Buffer, Promega), $3 \mu \mathrm{L}$ of $\mathrm{MgCl}_{2}$ (25 mM; Promega), $0.25 \mu \mathrm{L}$ bovine serum albumin (10 $\mu \mathrm{g} \mu \mathrm{L}^{-1}$; Promega), $0.5 \mu \mathrm{L}$ dNTP (10 mM; Thermo Scientific), $0.5 \mu \mathrm{L}$ of each primer $(5 \mu \mathrm{M}$; Integrated DNA Technologies), $0.1 \mu \mathrm{L}$ of DNA polymerase $\left(5 \mathrm{U} \mu \mathrm{L}^{-1}\right.$; GoTaq Flexi DNA polymerase, Promega), $13.15 \mu \mathrm{L} \mathrm{H}_{2} \mathrm{O}$, and $2 \mu \mathrm{L}$ template DNA. Bacterial and fungal PCR products were then run on a $0.5 \%$ agarose gel, purified with a QIAquick Gel Extraction Kit (Qiagen), and eluted in $30 \mu \mathrm{L}$ at the final step. Standards were quantified using the Qubit dsDNA BR Assay Kit (Invitrogen, Life Technologies) and a Qubit 2.0 Fluorometer (Qubit Systems) to determine the quantity of DNA in the final sample. The amplicon length was then used to calculate the number of copies per $\mu \mathrm{L}$, under the assumption that the molecular weight of each bp is 650 . A standard curve was generated using 10-fold dilutions of these standards across 8 orders of magnitude, therefore standardizing qPCR results by copy number.

Each plate included triplicate reactions per DNA sample and for the standard curve, as well as a no-template control to check for contamination. A melt curve $\left(1 \mathrm{~min}\right.$ at $95^{\circ} \mathrm{C}, 1 \mathrm{~min}$ at

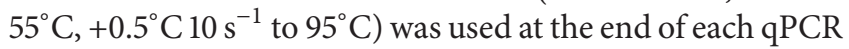
run to ensure the fluorescence signal resulted from specificity to the PCR product rather than from primer dimers or other nonspecific products. The fluorescein dye included in the master mix allowed for standard normalization of error across samples. Threshold cycles (Ct) were automatically calculated by the software based on the average background noise. Samples with less than one order of magnitude of separation (3.3 Ct value) from the no-template control were excluded given that this was outside of the detection limit of the present analysis $[35,36]$. These samples were therefore reanalyzed using the same standard curve with a less dilute template in order to ensure accurate quantification. Samples that fell below the detection limit regardless of dilution were excluded from the analysis.

2.10. Statistical Analysis. Statistical analyses were conducted using JMP 10 (SAS Institute, http://www.jmp.com/). Hatching success, temperature, $\mathrm{pO}_{2}$, bacterial and fungal abundance, organic matter content, and mean grain size data were all analyzed using ANOVA. When assumptions of normality and homogeneity of variance were not met, nonparametric tests were used (Wilcoxon/Kruskal-Wallis). Statistically significant results were further tested with Tukey's HSD post hoc test to determine significant differences between beach areas. Relationships between variables (hatching success, $\mathrm{pO}_{2}$, temperature, grain size, organic matter content, and bacterial and fungal abundance) were evaluated using Spearman's rank correlation coefficients.

Because the metabolic demand of sea turtle embryos is low within the first half of incubation given their limited development, differences in oxygen content and temperature in the egg clutch within this time period can presumably be attributed to microbial activity $[8,37]$. Mean nest $\mathrm{pO}_{2}$ and temperature were therefore analyzed for the first and second half of incubation separately. Repeated measurements of temperature and oxygen were also analyzed with repeated measures MANOVA. To allow for sample comparison across qPCR plates, an ANCOVA was used to ensure there was no significant difference between standard curves from different runs. We also used a positive control on each plate to calculate a coefficient of variation $(\mathrm{CV})$ in order to ensure reproducibility within and between all plates. All values are expressed as means \pm standard error (SE). Percentage data (hatching success) and microbial abundance data (copy number) were arcsine- and log-transformed, respectively, before analysis with parametric statistics. Mean grain size was converted from phi units $(\phi)$ to $\mathrm{mm}$ for presentation. The number of $16 \mathrm{~S} / 18 \mathrm{~S}$ copies $\mathrm{ul}^{-1}$ of template was converted to a number of $16 \mathrm{~S} / 18 \mathrm{~S}$ copies $\mathrm{g}^{-1}$ of nest sand to allow for comparison across samples. All analyses were tested for statistical significance at $\alpha<0.05$.

\section{Results}

The sample arribada occurring in August 2012 (estimated at 72,152 egg-laying females) and another arribada (September 2012, estimated at 211,954 egg-laying females) occurring before nest excavations were carried out in the middle of October. An earthquake measuring 7.6 on the Richter scale occurred on September 5, 2012, the epicenter located approximately $50 \mathrm{~km}$ south of Ostional, which caused visible structural changes to the beach topography. Nest density for the entire beach at the time of excavation was $3.6 \pm 0.4$ nests $\mathrm{m}^{-2}$ and overall hatching success for nests laid on the main nesting beach during the August arribada was $34 \pm 5.4 \%$ (R. Valverde, unpublished data). At the time of excavation, the nest densities in the high-nest-density, tidal-wash, and lownest-density areas were $5.2 \pm 0.4,2.0 \pm 0.6$, and $3.0 \pm 0.5$ nests $\mathrm{m}^{-2}$, respectively. Two nests were excluded from the analysis due to unforeseeable factors that likely caused a change in the variables that we attempted to control in this study (i.e., temperature and $\mathrm{pO}_{2}$ of the nest). Specifically, we excluded a nest in the high-density nesting area that was partially shaded by a palm tree and another in the tidal-wash nesting area that remained permanently inundated by the nearby estuary after the earthquake. Hatching success in the high-nest-density area $(0.6 \%)$ was significantly lower than in the low-nestdensity $(68.2 \%)$ and tidal-wash $(54.7 \%)$ areas of the beach $(P<0.001$, Figure 1$)$.

The $\mathrm{pO}_{2}$ within egg clutches in the high-nest-density area was significantly lower than that in other areas of the beach in both the first $(15.4 \pm 0.9 \mathrm{kPa}, P<0.001)$ and second half of incubation $(11.5 \pm 0.5 \mathrm{kPa}, P<0.001$; Figure 2$)$. The mean minimum $\mathrm{pO}_{2}$ among nests in the high-nest-density area was $9.7 \pm 0.3 \mathrm{kPa}$, with one clutch exhibiting $\mathrm{pO}_{2}$ as low as $8.7 \mathrm{kPa}$. Nest $\mathrm{pO}_{2}$ varied significantly with beach area and incubation day, with a significant interaction occurring between these two factors $\left(F_{2,10}=45.997, P<0.001 ; F_{9,2}=24.846\right.$, $P=0.039 ; F_{18,4}=3.069, P=0.012$, resp.). Hatching success was positively correlated with $\mathrm{pO}_{2}$ in both the first and second half of the incubation period $(r=0.872, P<0.0001$ and $r=0.591, P=0.020$, resp., Table 1$)$. 


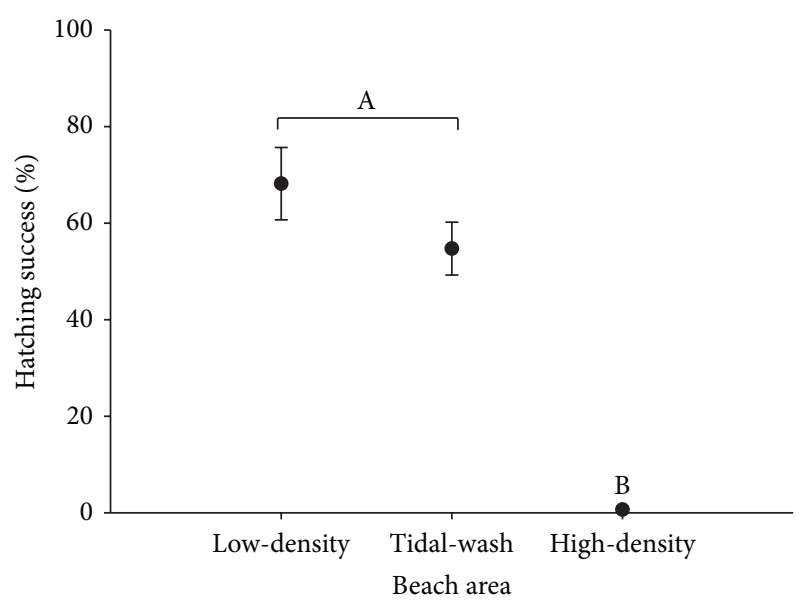

FIGURE 1: Mean $( \pm$ SE) hatching success of nests located in different nesting areas of the beach $(n=5)$. Different letters denote statistical difference. Hatching success in the high-nest-density area $(0.6 \%)$ was significantly lower than in the low-nest-density $(68.2 \%)$ and tidal-wash $(54.7 \%)$ areas of the beach $(P<0.001)$.

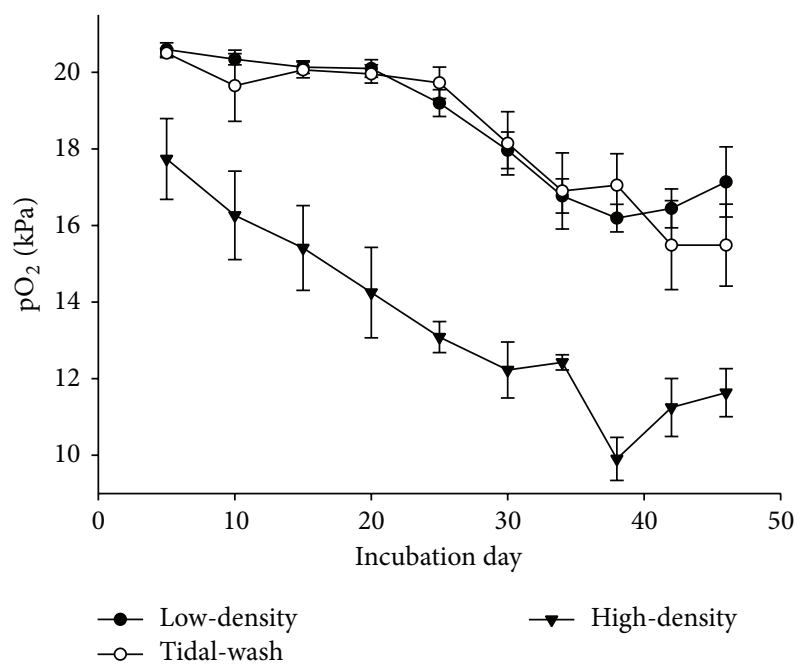

FIgURE 2: Mean ( \pm SE) partial pressure of oxygen $\left(\mathrm{pO}_{2}, \mathrm{kPa}\right)$ in nests throughout the incubation period for nests located in the high-density, tidal-wash, and low-density nesting areas of the beach $(n=5)$. The $\mathrm{pO}_{2}$ within nests in the high-nest-density area was significantly lower than that in other areas of the beach in both the first and the second half of incubation $(P<0.001$ and $P<0.0001$, resp.).

Nest temperatures were significantly lower in the tidalwash area in the first and second half of incubation $(P=0.001$ and $P=0.001$, resp., Figure 3 ). Temperatures in the highnest-density area of the beach were the highest in the second half of incubation $\left(35.7 \pm 0.2^{\circ} \mathrm{C}\right)$ and remained above the lethal limit $\left(35^{\circ} \mathrm{C},[38]\right)$ for a significantly longer duration of time in comparison to other areas of the beach $(17.0 \pm 0.7 \mathrm{~d}, P=$ $0.009)$. Nest temperature varied significantly with beach area and incubation day, with a significant interaction occurring between these two factors $\left(F_{2,9}=16.949, P=0.001 ; F_{47,423}=\right.$ 78.396, $P<0.001 ; F_{94,423}=2.880, P<0.001$, resp. $)$.
TABLE 1: Relationships between hatching success and partial pressure of oxygen $\left(\mathrm{pO}_{2}\right)$ and temperature in the first (1st) and second (2nd) half of incubation, bacterial and fungal abundance, and organic matter content for all study nests. Copy number data from several nests fell outside the range of detection for the present analysis and were therefore left out (see Section 3 for more details). Hatching success was positively correlated with nest $\mathrm{pO}_{2}$ in both the first and second half of incubation and negatively correlated with the bacterial abundance in nest sand.

\begin{tabular}{lcccc}
\hline \multirow{2}{*}{ Variable } & Half of incubation & \multicolumn{3}{c}{ Hatching success } \\
& period & $r$ & $n$ & $P$ \\
\hline $\mathrm{pO}_{2}$ & 1st & 0.872 & 13 & $<\mathbf{0 . 0 0 1}$ \\
& 2nd & 0.591 & 13 & $\mathbf{0 . 0 2 0}$ \\
\hline \multirow{2}{*}{ Temperature } & 1 st & -0.025 & 13 & 0.929 \\
& 2nd & -0.207 & 13 & 0.459 \\
\hline Bacterial abundance & & -0.585 & 12 & $\mathbf{0 . 0 4 6}$ \\
\hline Fungal abundance & & -0.607 & 10 & 0.063 \\
\hline Organic matter content & & -0.392 & 13 & 0.185 \\
\hline
\end{tabular}

$r$ : Spearman's rank correlation coefficient and $n$ : sample size. Values in bold indicate statistically significant correlations.

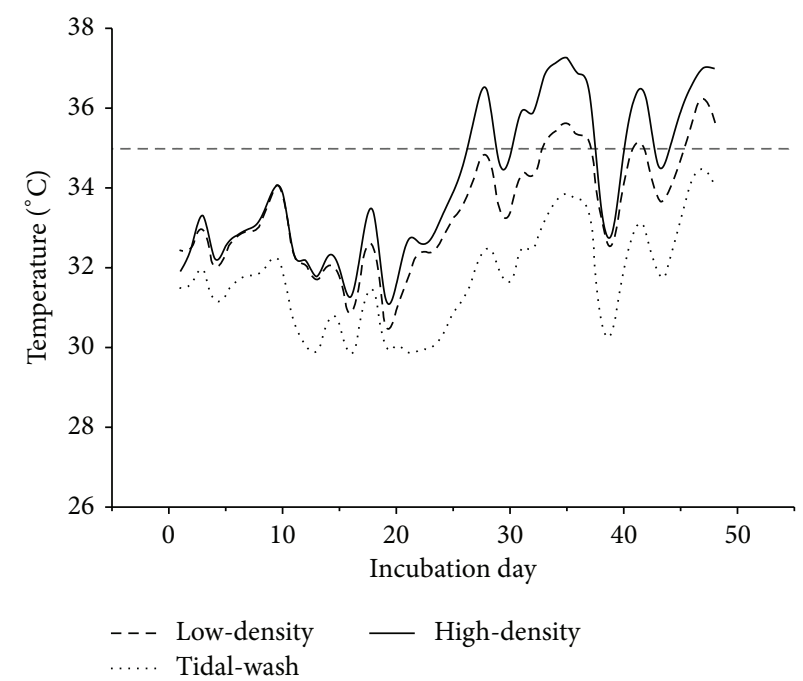

FIgURE 3: Mean nest temperature throughout the incubation period in nests located in the high-density, tidal-wash, and low-density nesting areas of the beach $(n=5)$. The field lethal incubation temperature is indicated with a horizontal grey dashed line $\left(35^{\circ} \mathrm{C}\right.$, Valverde et al., 2010). Nest temperatures were significantly lower in the tidal-wash area in the first and the second half of incubation $(P=0.001$ and $P=0.001$, resp. $)$.

However, hatching success was not significantly correlated with nest temperatures in the first or second half of incubation (Table 1).

The organic matter content of nest sand was significantly higher in the high-nest-density area $(4.0 \%)$ than in the lownest-density (3.2\%) and tidal-wash (3.0\%) areas of the beach $(P=0.015$ and $P=0.003$, resp.). The sand from nests in the low-nest-density area had a significantly larger mean grain size $(0.366 \mathrm{~mm})$ than in both the high-nest-density $(0.282 \mathrm{~mm})$ and tidal-wash $(0.283 \mathrm{~mm})$ areas of the beach 
( $P=0.020$ for both comparisons). Additionally, the sand from all nests in the high-nest-density, tidal-wash, and lownest-density areas of the beach was moderately sorted $\left(\sigma_{\phi} 1.0\right.$, 1.01 , and 0.98 , resp.) and finely skewed $\left(\mathrm{Sk}_{\phi} 0.35,0.36\right.$, and 1.03 , resp.).

There was no significant difference in the slope of the standard curve across assays for bacteria $(E=102.23 \pm 1.41 \%$, $R^{2}=0.99$, slope $=-3.27 \pm 0.03$, intercept $=36.83 \pm 0.56, \mathrm{CV}=$ $3.41 \%)$ or fungi $\left(E=84.55 \pm 2.25 \%, R^{2}=1.00 \pm 0.00\right.$, slope $=$ $-3.76 \pm 0.07$, intercept $=48.52 \pm 0.80, \mathrm{CV}=1.68 \%)$, indicating that copy numbers were comparable across assays $(P=0.856$ and $P=0.088$, resp.). Microscopy counts (range $5.72 \times 10^{6}$ $7.43 \times 10^{7}$ cells $^{-1}$ of nest sand) were closely correlated with qPCR results for $16 \mathrm{~S}$ rRNA gene copy number $\mathrm{g}^{-1}$ of sand for all nests $(r=0.404, P=0.013)$. Both the $16 \mathrm{~S}$ and $18 \mathrm{~S}$ copy numbers for one nest in the low-nest-density area as well as the $18 \mathrm{~S}$ copy number for two nests in the tidal-wash area were below the detection limit of the present analysis and were therefore omitted.

There was a significantly higher abundance of bacteria in nest sand from the high-nest-density area in comparison to other areas of the beach $(P=0.029)$. There was also a higher abundance of fungi in nest sand from the high-nestdensity area of the beach, though this difference was marginal $(P=0.063)$. While there was a negative correlation between hatching success and bacterial abundance for all nests, the correlation between hatching success and fungal abundance was marginal $(r=-0.585, P=0.046$ and $r=-0.607$, $P=0.063$, resp., Table 1 and Figure 4). There was a negative correlation between the number of bacteria and egg clutch $\mathrm{pO}_{2}$ in both the first and second half of incubation $(r=$ $-0.741, P=0.006$ and $r=-0.797, P=0.002$, resp.) as well as a positive correlation between the number of bacteria and nest temperatures in the second half of incubation $(r=$ $0.818, P=0.001$, Table 2 ). Furthermore, there was a positive correlation between bacterial abundance and organic matter content in nest sand across all areas of the beach $(r=0.636$, $P=0.026)$.

\section{Discussion}

In this study, we monitored nest conditions throughout the incubation period and quantified the microbial abundance of nest sand in association with sea turtle hatching success. We found a negative relationship between the microbial abundance of nest sand and hatching success and observed significantly low $\mathrm{pO}_{2}$ in egg clutches located in the highnest-density area of the beach. Egg clutches located in the tidal-wash area of the beach had higher hatching success and $\mathrm{pO}_{2}$ as well as lower organic matter content than those located in the high-nest-density area of the beach. These results are consistent with previous reports that seawater may have a positive effect on hatching success [39, 40], presumably by decreasing microbial abundance, incubation temperature, and/or organic matter content. Our results also support our hypothesis that the low $\mathrm{pO}_{2}$ associated with high microbial abundance in nest sand is responsible for the lower hatching rates observed at Ostional beach. Collectively,

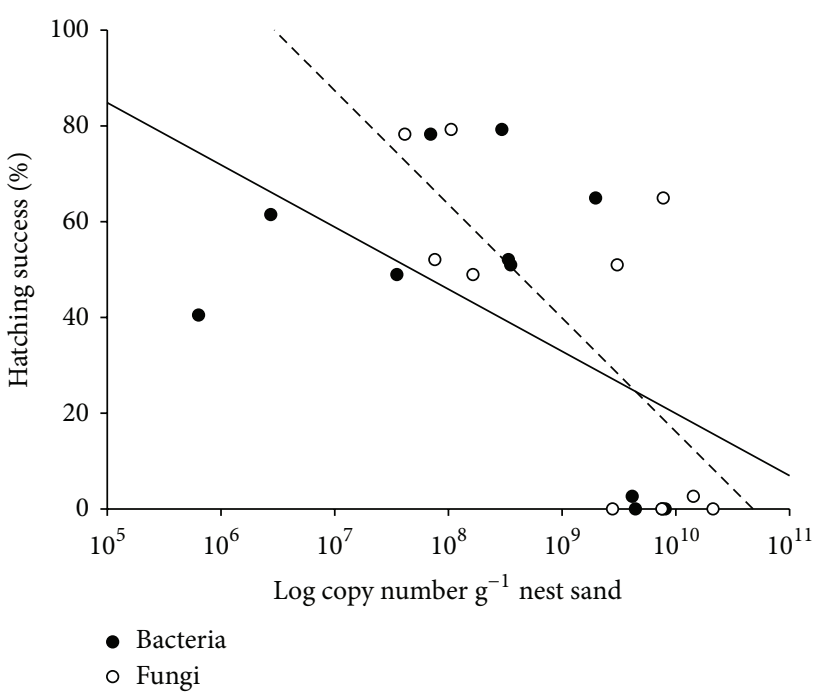

FIGURE 4: Relationship between hatching success and microbial abundance (bacteria and fungi) for nests located in each nesting area of the beach ( $n=12$ and $n=10$, resp.). Regression lines for bacteria (solid) and fungi (dashed) are included for visualization purposes. While there was a negative correlation between hatching success and bacterial abundance for all nests, the correlation between hatching success and fungal abundance was marginal $(P=0.046$ and $P=0.063$, resp.). For Spearman's rank correlation coefficients, see Table 1.

these data suggest a nonpathogenic mechanism for sea turtle embryonic mortality resulting from high rates of microbial decomposition altering the nest environment beyond the optimal range for embryonic development.

Because all nests in this study incubated during the same time period, we are fairly confident that a majority of factors affecting embryonic development and hatching success were reasonably controlled. However, there may be factors that we did not monitor that caused incongruences in nest conditions and could have influenced hatching success in this study. Additionally, an earthquake of large magnitude, such as the one that occurred during this study, could have feasibly caused movement-induced mortality of sea turtle embryos. However, the earthquake occurred on day 25 of incubation, after the critical period ( $12 \mathrm{~h}$ to $14 \mathrm{~d}$ ) during which movement significantly reduced hatching success [41], and therefore likely had no adverse effects on the egg clutches in this study.

4.1. Hatching Success. Hatching success was highest in nests located in the low-nest-density area. High-nest-densities have previously been observed to have direct physiological effects (i.e., lower $\mathrm{pO}_{2}$ and higher $\mathrm{pCO}_{2}$ within the egg clutch) that negatively impacted hatching success [4]. Nest densities of up to 5 nests $\mathrm{m}^{-2}$ are unlikely to have a significant effect on hatching success $(\geq 56 \%)$, while densities of 9 nests $\mathrm{m}^{-2}$ may significantly reduce hatching success to $30 \%$ [4]. However, the nests in this study were subject to relatively low-nest-densities (2-5 nests $\mathrm{m}^{-2}$ ), which likely were not high enough to cause the significant drop in hatching success observed. 
TABLE 2: Relationships between bacterial and fungal abundance and the partial pressure of oxygen $\left(\mathrm{pO}_{2}\right)$ and temperature in the first (1st) and second ( $2 \mathrm{nd}$ ) half of incubation for all study nests. There was a negative correlation between bacterial abundance and nest $\mathrm{pO}_{2}$ in both the first and second half of incubation and a positive correlation with nest temperatures in the second half of incubation. There was also a negative correlation between fungal abundance and nest $\mathrm{pO}_{2}$ in the first half of incubation.

\begin{tabular}{|c|c|c|c|c|c|c|c|c|c|}
\hline \multirow{3}{*}{ Microbial abundance } & \multirow{3}{*}{$n$} & \multicolumn{4}{|c|}{$\mathrm{pO}_{2}$} & \multicolumn{4}{|c|}{ Temperature } \\
\hline & & \multicolumn{2}{|c|}{1 st } & \multicolumn{2}{|c|}{ 2nd } & \multicolumn{2}{|c|}{1 st } & \multicolumn{2}{|c|}{ 2nd } \\
\hline & & $r$ & $P$ & $r$ & $P$ & $r$ & $P$ & $r$ & $P$ \\
\hline Bacteria & 12 & -0.741 & 0.006 & -0.797 & 0.002 & 0.441 & 0.152 & 0.818 & 0.001 \\
\hline Fungi & 10 & -0.746 & 0.013 & -0.455 & 0.187 & 0.430 & 0.215 & 0.430 & 0.215 \\
\hline
\end{tabular}

$r$ : Spearman's rank correlation coefficient and $n$ : sample size. Values in bold indicate statistically significant correlations.

4.2. Nest Oxygen Content. $\mathrm{pO}_{2}$ for the low-nest-density and tidal-wash areas of the beach was similar to that previously observed in other studies on olive ridley sea turtles $[4,8]$. Those studies also observed a change in the $\mathrm{pO}_{2}$ of nests over the incubation period, with $\mathrm{pO}_{2}$ decreasing later in the incubation period as a result of embryo respiration. The significant interaction effect of beach area and incubation day on egg clutch $\mathrm{pO}_{2}$ indicates that the $\mathrm{pO}_{2}$ within egg clutches changed differently across the areas of the beach.

On the other hand, the $\mathrm{pO}_{2}$ observed in egg clutches located in the high-nest-density area in this study is lower than that previously observed in other studies $[8,22,42]$. Specifically, the drop in $\mathrm{pO}_{2}$ that we observed early in the incubation period is uncharacteristic of sea turtle egg clutches given that the metabolic activity of the embryos is typically negligible at this time [42]. Clutch $\mathrm{pO}_{2}$ typically remains constant through the first half of incubation and then decreases and tends to be negatively correlated with the number of metabolizing embryos per clutch $[8,22]$. However, this was not the case for clutches located in the high-nestdensity area of the beach where $\mathrm{pO}_{2}$ began to drop from the start of incubation and was lower in both the first and second half of the incubation period in comparison to other areas of the beach.

The negative correlation between microbial abundance (of both bacteria and fungi) and clutch $\mathrm{pO}_{2}$ at Ostional suggests that microbial decomposition was responsible for these decreases in $\mathrm{pO}_{2}$. In particular, our observations of high abundance of bacteria and organic matter in nest sand from the high-nest-density area of the beach in association with low $\mathrm{pO}_{2}$ further support this hypothesis. Additionally, if this decrease in $\mathrm{pO}_{2}$ resulted from the decomposition of embryos killed by pathogens in these nests, one would expect a lag time (i.e., time for infection) and an abrupt change in oxygen and temperature following embryo death. Furthermore, while nest density alone affects the oxygen content of nests, the minimum $\mathrm{pO}_{2}$ observed in the high-nest-density area $(9.7 \mathrm{kPa})$ in this study was lower than previously observed at similar and even higher nest densities (approximately $14.5-17.0 \mathrm{kPa})[4,8]$. Given that these previous studies in "clean" sand (with presumably low organic matter content) did not find such discrepancies in the $\mathrm{pO}_{2}$ of egg clutches at similar densities, it is likely that microbial decomposition is responsible for the differences observed here. However, further studies that include a controlled measure of $\mathrm{pO}_{2}$ in beach sand outside of egg clutches and within egg clutches at controlled densities are necessary to properly test this hypothesis.

Because sea turtle embryos have a relatively low tolerance to hypoxia early in the incubation period [43], it is likely that the drop in $\mathrm{pO}_{2}$ that we observed in the high-nestdensity area of the beach led to total nest failure. While the critical oxygen tension of olive ridley sea turtle eggs has not been studied, this value was as high as $16.5 \mathrm{kPa}$ on day 22 of incubation for loggerhead sea turtle (Caretta caretta) eggs, which are comparable in size [43]. Assuming that the critical oxygen tension of olive ridley sea turtle eggs is similar and given that egg clutch $\mathrm{pO}_{2}$ fell below $16.5 \mathrm{kPa}$ on day 15 of incubation in the high-nest-density area, it is likely that any eggs located here were exposed to $\mathrm{pO}_{2}$ below a lethal threshold.

4.3. Nest Temperature. The nest temperatures observed in this study are similar to those observed in other studies on olive ridley sea turtles in this region $[4,8,38]$. In general, mean incubation temperatures were above the mean pivotal temperature of $30.5^{\circ} \mathrm{C}$ for olive ridleys [44, 45], indicating that the hatchling sex ratio could be female-biased at Ostional, as previously suggested [38]. Previous studies have also observed a change in nest temperatures throughout the incubation period, with temperatures increasing later in incubation in conjunction with increasing embryonic metabolism $[4,8]$. Nest temperatures were fairly consistent across the different areas of the beach throughout the incubation period, with the exception of nests located in the tidal-wash area, where lower nest temperatures likely resulted from higher water content in the sand. The incubation period was 2 to 3 days longer in this group of nests and is likely a result of slower embryonic development due to lower nest temperatures [46].

While most nest temperatures fell within the wide range of tolerance for sea turtle embryological development (25$35^{\circ} \mathrm{C}$, [39]) early in the incubation period, the slightly higher temperatures observed in the high-nest-density area of the beach later in incubation may have exceeded this optimal range long enough to affect hatching success. Though the field lethal limit for olive ridley sea turtles at this beach is approximately $35^{\circ} \mathrm{C}$, embryos may be capable of recovering from short-term exposure to high temperatures while longer durations are lethal [38]. Results from this study support this notion, in that nests with lower hatching success (highnest-density area) were also exposed to temperatures above 
the lethal limit for a longer duration of time. The different combination of heat released from embryonic metabolism and/or microbial decomposition is likely responsible for the observed differences in temperature later in incubation.

4.4. Characteristics of Nest Sand. The mean grain size and sorting coefficient of sand from nests in this study were comparable to those previously observed at a variety of sea turtle nesting beaches [47]. Given the relatively small range of mean grain size observed across study nests (0.282$0.366 \mathrm{~mm}$ ), granulometry likely did not drive the differences in hatching success across the areas of the beach.

The high amounts of organic matter in the sand from this study in comparison to other sea turtle nesting beaches [47] are not surprising as this is likely a result of the high rates of nest destruction due to the large number of nesting females and high-nest-density at this beach $[9,19,48]$. The association of high organic matter content with a higher abundance of bacteria in the sand from the high-nest-density area in this study supports the hypothesis that high organic matter is associated with elevated microbial proliferation and decomposition at Ostional and may also explain the low egg clutch $\mathrm{pO}_{2}$ in comparison to previous studies $[7,8]$.

4.5. Microbial Abundance. The number of bacterial $16 \mathrm{~S}$ and fungal $18 \mathrm{~S}$ rRNA gene copies in this study ranged from $10^{5}$ to $10^{10}$ copies $\mathrm{g}^{-1}$ of sea turtle nest sand. A previous study found that the sand at an arribada beach contained six orders of magnitude more bacterial colonies $\mathrm{g}^{-1}$ in comparison to a neighboring beach, although no specific abundance data were provided $[10,14]$. Previous studies that have quantified $16 \mathrm{~S}$ or $18 \mathrm{~S}$ rRNA gene copies in similar sediments have found between $10^{6}$ and $10^{9}$ copies $g^{-1}[26,49]$.

The negative relationship between bacterial abundance and hatching success that we observed supports the hypothesis that the microbial abundance in nest sand at Ostional is high enough to adversely affect embryonic development. Specifically, we suggest that the mechanism behind this relationship is not pathogenic but rather a result of high rates of microbial decomposition of organic matter altering the nest environment beyond the optimal range for embryonic development. Studies on underground nesting species of birds and reptiles suggest similar influences of microbial decomposition on nest $\mathrm{pO}_{2}$ and temperature $[50,51]$. It is possible that the relationship between microbial activity and hatching success is nonlinear, with a threshold beyond which high rates of microbial respiration disrupt the diffusion of oxygen to the nest to the point of impeding embryonic development. For example, the relationship between microbial abundance and hatching success appears to reach a threshold at $\sim 1 \times 10^{9}-10^{10} 16 \mathrm{~S} / 18 \mathrm{~S}$ copies $\mathrm{g}^{-1}$ nest sand. Further studies that span a broader range in microbial abundance are required to confirm the true nature of the relationship between the microbial abundance of nest sand and sea turtle hatching success. The coinciding occurrence of lower $\mathrm{pO}_{2}$, higher temperatures, higher organic matter, and low hatching success in the high-nest-density area of the beach serves as an extreme example of the adverse conditions imposed by microbial decomposition at Ostional.
In addition to the indirect effect of microbial abundance on the nest environment, there are likely other effects of microbial presence on sea turtle hatching success that we did not consider because they were not within the scope of the present study. For example, we did not explore species composition or diversity nor did we evaluate the presence or absence of pathogens. The potential presence of pathogenic microbes in the sand at Ostional cannot be ruled out. Several species of fungi in the Fusarium solani species complex have been identified as pathogens to sea turtle eggs and are known to occur at nesting beaches around the world $[15,16]$. It is also possible that the effects of microbial abundance and the nest environment on hatching success are synergistic with the effects of lethal pathogens [15]. For example, once embryos are killed due to the adverse effects of microbial oxygen depletion on the nest environment, this may result in the proliferation of fungi, which could then spread to adjacent eggs. Further studies should therefore focus on sampling from several components of the nest environment (i.e., cloacal fluid, nest sand, eggshell, unhatched embryos, and live hatchlings), as well as assessing the abundance, diversity, and activity of both fungi and bacteria to provide a more complete understanding of the relationship between microbial activity and the reproductive success of sea turtles.

Based on our comparative study, it appears that tidal washing decreases the organic matter and microbial abundance in the sand, thus increasing hatching success. Alternatively, the high humidity in the sand resulting from tidal washing may also keep incubation temperatures from reaching lethal temperatures. Therefore, seawater inundation may be critical in maintaining the population of sea turtles at Ostional. Using these natural mechanisms as a model for conservation, management practices could be adopted to promote improved embryo survival and hatchling production. For example, seawater could be used to decrease organic matter and microbial abundance in hatchery sand or by periodically irrigating the beach with seawater. The treatment of sand or relocation of hatcheries on a regular basis is a conventional management practice in conservation programs to avoid organic matter build-up as well as microbial and larval infestations. In fact, the leatherback sea turtle conservation program at Ostional successfully increased hatching success in the leatherback hatchery by using sand from below the high tide line [40].

\section{Conflict of Interests}

The authors declare that there is no conflict of interests regarding the publication of this paper.

\section{Acknowledgments}

The authors would like to thank G. Bran, Y. Argüello-Gómez, M. Gómez, S. Steele, and all the employees and volunteers at RNVS Ostional for their help in the field. The authors would also like to thank S. Berthrong, A. Oporta McCarthy, and R. Leisen for their contributions to the molecular and laboratory analyses. This material is based upon work supported by the 
National Science Foundation Graduate Research Fellowship under Grant no. 511182. Additional funds to support the lab and field research for this study were provided by the PADI Foundation, National Geographic Young Explorers Grant (C220-12), USFWS Marine Turtle Conservation Act (96200$0-$ G037), and internal grants from the College of Charleston. This research was approved by the College of Charleston IACUC and permits were granted by MINAET (Resolución no. ACT-OR-DR-078) and CONAGEBio (R-020-2012-OTCONAGEBIO) of Costa Rica.

\section{References}

[1] A. Abreu-Grobois and P. T. Plotkin, "IUCN SMTSG (2008) Lepidochelys olivacea," The IUCN Red List of Threatened Species, Version 2014.2, http://www.iucnredlist.org/.

[2] R. A. Valverde, C. M. Orrego, M. T. Tordoir et al., "Olive ridley mass nesting ecology and egg harvest at ostional beach, Costa Rica," Chelonian Conservation and Biology, vol. 11, no. 1, pp. 1-11, 2012.

[3] S. E. Cornelius, R. Arauz, J. Fretey et al., "Effect of land based harvest of Lepidochelys," in The Biology and Conservation of Ridley Sea Turtles, P. T. Plotkin, Ed., pp. 231-251, Johns Hopkins University Press, Baltimore, Md, USA, 2007.

[4] S. Honarvar, M. P. O'Connor, and J. R. Spotila, "Densitydependent effects on hatching success of the olive ridley turtle, Lepidochelys olivacea," Oecologia, vol. 157, no. 2, pp. 221-230, 2008.

[5] V. S. Beézy and R. A. Valverde, "A comparison of methodologies for estimating the nest density of olive ridley arribadas at Ostional, Costa Rica," in Proceedings of the 31st Annual Symposium on Sea Turtle Biology and Conservation, T. T. Jones and B. P. Wallace, Eds., NOAA Technical Memorandum NMFS-SEFSC631, pp. 194-195, 2012.

[6] S. E. Cornelius, M. A. Ulloa, J. C. Castro, M. Mata del Valle, and D. C. Robinson, "Management of olive ridley sea turtles (Lepidochelys olivacea) nesting at Playas Nancite and Ostional, Costa Rica," in Neotropical Wildlife Use and Conservation, J. Robinson and K. Redford, Eds., vol. 1, pp. 111-135, University of Chicago Press, Chicago, Ill, USA, 1991.

[7] R. A. Valverde, S. E. Cornelius, and C. L. Mo, "Decline of the olive ridley sea turtle (Lepidochelys olivacea) nesting assemblage at Nancite Beach, Santa Rosa National Park, Costa Rica," Chelonian Conservation and Biology, vol. 3, pp. 58-63, 1998.

[8] S. Clusella Trullas and F. V. Paladino, "Micro-environment of olive ridley turtle nests deposited during an aggregated nesting event," Journal of Zoology, vol. 272, no. 4, pp. 367-376, 2007.

[9] D. McPherson and D. Kibler, "Ecological impact of olive ridley nesting at Ostional, Costa Rica," in Proceedings of the 25th Annual Symposium on Sea Turtle Biology and Conservation, H. Kalb, A. Rohde, K. Gayheart, and K. Shanker, Eds., NOAA Technical Memorandum NMFS-SEFSC-582, p. 204, 2008.

[10] C. L. Mo, I. Salas, and M. Caballero, "Are fungi and bacteria responsible for olive ridley's egg loss?" in Proceedings of the 10th Annual Workshop on Sea Turtle Biology and Conservation, T. H. Richardson, J. I. Richardson, and M. Donnelly, Eds., pp. 249252, NOAA Techn, 1990.

[11] S. Honarvar, J. R. Spotila, and M. P. O’Connor, "Microbial community structure in sand on two olive ridley arribada nesting beaches, Playa La Flor, Nicaragua and Playa Nancite, Costa
Rica," Journal of Experimental Marine Biology and Ecology, vol. 409, no. 1-2, pp. 339-344, 2011.

[12] A. D. Phillott and C. J. Parmenter, "The distribution of failed eggs and the appearance of fungi in artificial nests of green (Chelonia mydas) and loggerhead (Caretta caretta) sea turtles," Australian Journal of Zoology, vol. 49, no. 6, pp. 713-718, 2001.

[13] J. Wyneken, T. J. Burke, M. Salmon, and D. K. Pedersen, "Egg failure in natural and relocated sea turtle nests," Journal of Herpetology, vol. 22, no. 1, pp. 88-96, 1988.

[14] C. L. Mo, M. Caballero, and I. Salas, "Microorganism infection of olive ridley eggs," in Proceedings of the 12th Annual Workshop on Sea Turtle Biology and Conservation, J. I. Richardson and T. H. Richardson, Eds., NOAA Technical Memorandum NMFSSEFSC-361:274, pp. 81-84, 1995.

[15] J. M. Sarmiento-Ramírez, E. Abella, M. P. Martín et al., "Fusarium solaniis responsible for mass mortalities in nests of loggerhead sea turtle, Caretta caretta, in Boavista, Cape Verde," FEMS Microbiology Letters, vol. 312, no. 2, pp. 192-200, 2010.

[16] J. M. Sarmiento-Ramírez, E. Abella-Pérez, A. D. Phillott et al., "Global distribution of two fungal pathogens threatening endangered sea turtles," PLoS ONE, vol. 9, Article ID e85853, 2014.

[17] J. Patino-Martinez, A. Marco, L. Quiñones, E. Abella, R. M. Abad, and J. Diéguez-Uribeondo, "How do hatcheries influence embryonic development of sea turtle eggs? Experimental analysis and isolation of microorganisms in leatherback turtle eggs," Journal of Experimental Zoology Part A: Ecological Genetics and Physiology, vol. 317, no. 1, pp. 47-54, 2012.

[18] A. D. Phillott and C. J. Parmenter, "Fungal colonization of green sea turtle (Chelonia mydas) nests is unlikely to affect hatchling condition," Herpetological Conservation \& Biology, vol. 9, pp. 297-301, 2014.

[19] M. Ocana, M. Harfush-Melendez, and S. Heppell, "Mass nesting of olive ridley sea turtles Lepidochelys olivacea at La Escobilla, Mexico: linking nest density and rates of destruction," Endangered Species Research, vol. 16, pp. 45-54, 2012.

[20] D. Madden, J. Ballestero, C. Calvo, R. Carlson, E. Christians, and E. Madden, "Sea turtle nesting as a process influencing a sandy beach ecosystem," Biotropica, vol. 40, no. 6, pp. 758-765, 2008.

[21] R. Valverde and C. Gates, "Population surveys on mass nesting beaches," in Research and Management Techniques for the Conservation of Sea Turtles, K. L. Eckert, K. A. Bjorndal, F. A. Abreu-Gobrois, and M. Donnelly, Eds., IUCN/SSC Marine Turtle Specialist Group Publication No. 4, 1999.

[22] B. P. Wallace, P. R. Sotherland, J. R. Spotila, R. D. Reina, B. F. Franks, and F. V. Paladino, "Biotic and abiotic factors affect the nest environment of embryonic leatherback turtles, Dermochelys coriacea," Physiological and Biochemical Zoology, vol. 77, no. 3, pp. 423-432, 2004.

[23] J. D. Miller, "Determining clutch size and hatching success," in Research and Management Techniques for the Conservation of Sea Turtles, K. L. Eckert, K. A. Bjorndal, F. A. Abreu-Grobois, and M. Donnelly, Eds., IUCN/SSC Marine Turtle Specialist Group Publication No. 4, 1999.

[24] S. J. Blott and K. Pye, "Gradistat: a grain size distribution and statistics package for the analysis of unconsolidated sediments," Earth Surface Processes and Landforms, vol. 26, no. 11, pp. 12371248,2001

[25] W. Krumbein and F. Pettijohn, Manual of Sedimentary Petrography, Appleton-Century-Crofts, New York, NY, USA, 1938. 
[26] N. C. Prévost-Bouré, R. Christen, S. Dequiedt et al., "Validation and application of a PCR primer set to quantify fungal communities in the soil environment by real-time quantitative PCR," PLoS ONE, vol. 6, no. 9, Article ID e24166, 2011.

[27] N. Fierer, J. A. Jackson, R. Vilgalys, and R. B. Jackson, “Assessment of soil microbial community structure by use of taxonspecific quantitative PCR assays," Applied and Environmental Microbiology, vol. 71, no. 7, pp. 4117-4120, 2005.

[28] A. Guidot, J.-C. Debaud, and R. Marmeisse, "Spatial distribution of the below-ground mycelia of an ectomycorrhizal fungus inferred from specific quantification of its DNA in soil samples," FEMS Microbiology Ecology, vol. 42, no. 3, pp. 477-486, 2002.

[29] T. B. de Gregoris, N. Aldred, A. S. Clare, and J. G. Burgess, "Improvement of phylum- and class-specific primers for realtime PCR quantification of bacterial taxa," Journal of Microbiological Methods, vol. 86, no. 3, pp. 351-356, 2011.

[30] E. J. Vainio and J. Hantula, "Direct analysis of wood-inhabiting fungi using denaturing gradient gel electrophoresis of amplified ribosomal DNA," Mycological Research, vol. 104, no. 8, pp. 927936, 2000.

[31] S. Turner, K. M. Pryer, V. P. W. Miao, and J. D. Palmer, "Investigating deep phylogenetic relationships among cyanobacteria and plastids by small subunit rRNA sequence analysis," The Journal of Eukaryotic Microbiology, vol. 46, no. 4, pp. 327-338, 1999.

[32] D. J. Lane, "16S/23S rRNA sequencing," in Nucleic acid Techniques in Bacterial Systematics, E. Stackebrandt and M. Goodfellow, Eds., pp. 115-174, John Wiley \& Sons, Chichester, UK, 1991.

[33] T. J. White, T. Bruns, S. Lee, and J. Taylor, "Amplification and direct sequencing of fungal ribosomal RNA genes for phylogenetics," in PCR Protocols: A Guide to Methods and Applications, pp. 315-322, 1990.

[34] N. Uemura, K. Makimura, M. Onozaki et al., "Development of a loop-mediated isothermal amplification method for diagnosing Pneumocystis pneumonia," Journal of Medical Microbiology, vol. 57, no. 1, pp. 50-57, 2008.

[35] C. J. Smith, D. B. Nedwell, L. F. Dong, and A. M. Osborn, "Evaluation of quantitative polymerase chain reaction-based approaches for determining gene copy and gene transcript numbers in environmental samples," Environmental Microbiology, vol. 8, no. 5, pp. 804-815, 2006.

[36] C. J. Smith and A. M. Osborn, "Advantages and limitations of quantitative PCR (Q-PCR)-based approaches in microbial ecology," FEMS Microbiology Ecology, vol. 67, no. 1, pp. 6-20, 2009.

[37] R. A. Ackerman, "Oxygen consumption by sea turtle (Chelonia, Caretta) eggs during development," Physiological Zoology, vol. 54, pp. 316-324, 1981.

[38] R. A. Valverde, S. Wingard, F. Gómez, M. T. Tordoir, and C. M. Orrego, "Field lethal incubation temperature of olive ridley sea turtle Lepidochelys olivacea embryos at a mass nesting rookery," Endangered Species Research, vol. 12, no. 1, pp. 77-86, 2010.

[39] L. G. Fonseca, W. N. Villachica, R. E. Matarrita, and R. A. Valverde, "Reporte final de la anidacioón de tortuga lora (Lepidochelys olivacea), Playa Nancite, Parque Nacional Santa Rosa, Costa Rica (Temporada 2010-2011)," Reporte Final de Temporada al USFWS, 2011.

[40] C. Figgener, A. Castillo-MacCarthy, J. Mora-Sandoval, Y. Argüelo-Gomez, and W. Quirós-Pereira, "Raising the hatching success of leatherback nests at the olive ridley mass-nesting beach in Ostional, Guanacaste, Costa Rica," in Proceedings of the 34th Annual Symposium on Sea Turtle Biology and Conservation, 2014.

[41] C. Limpus, V. Baker, and J. Miller, "Movement induced mortality of loggerhead eggs," Herpetologica, vol. 35, pp. 335-338, 1979.

[42] R. A. Ackerman, "The respiratory gas exchange of sea turtle nests (Chelonia, Caretta)," Respiration Physiology, vol. 31, no. 1, pp. 19-38, 1977.

[43] Y.-C. Kam, "Physiological effects of hypoxia on metabolism and growth of turtle embryos," Respiration Physiology, vol. 92, no. 2, pp. 127-138, 1993.

[44] T. Wibbels, D. Rostal, and R. Byles, "High pivotal temperature in the sex determination of the olive ridley sea turtle, Lepidochelys olivacea, from Playa Nancite, Costa Rica," Copeia, no. 4, pp. 1086-1088, 1998.

[45] C. J. McCoy, R. C. Vogt, and E. J. Censky, "Temperaturecontrolled sex determination in the sea turtle Lepidochelys olivacea," Journal of Herpetology, vol. 17, no. 4, pp. 404-406, 1983.

[46] N. A. Miller, " $\mathrm{PO}_{2}$ in loggerhead sea turtle (Caretta caretta) nests measured using fiber-optic oxygen sensors," Copeia, no. 4, pp. 882-888, 2008.

[47] J. A. Mortimer, "The influence of beach sand characteristics on the nesting behavior and clutch survival of green turtles (Chelonia mydas)," Copeia, vol. 1990, no. 3, pp. 802-817, 1990.

[48] S. E. Cornelius, The Sea Turtles of Santa Rosa National Park, Fundación de Parques Nacionales, San José, Costa Rica, 1986.

[49] X. Chen, E. Peltier, B. S. M. Sturm, and C. B. Young, "Nitrogen removal and nitrifying and denitrifying bacteria quantification in a stormwater bioretention system," Water Research, vol. 47, no. 4, pp. 1691-1700, 2013.

[50] R. S. Seymour and R. A. Ackerman, "Adaptations to underground nesting in birds and reptiles," American Zoologist, vol. 20, no. 2, pp. 437-447, 1980.

[51] R. S. Seymour, D. Vleck, and C. M. Vleck, "Gas exchange in the incubation mounds of megapode birds," Journal of Comparative Physiology B, vol. 156, no. 6, pp. 773-782, 1986. 

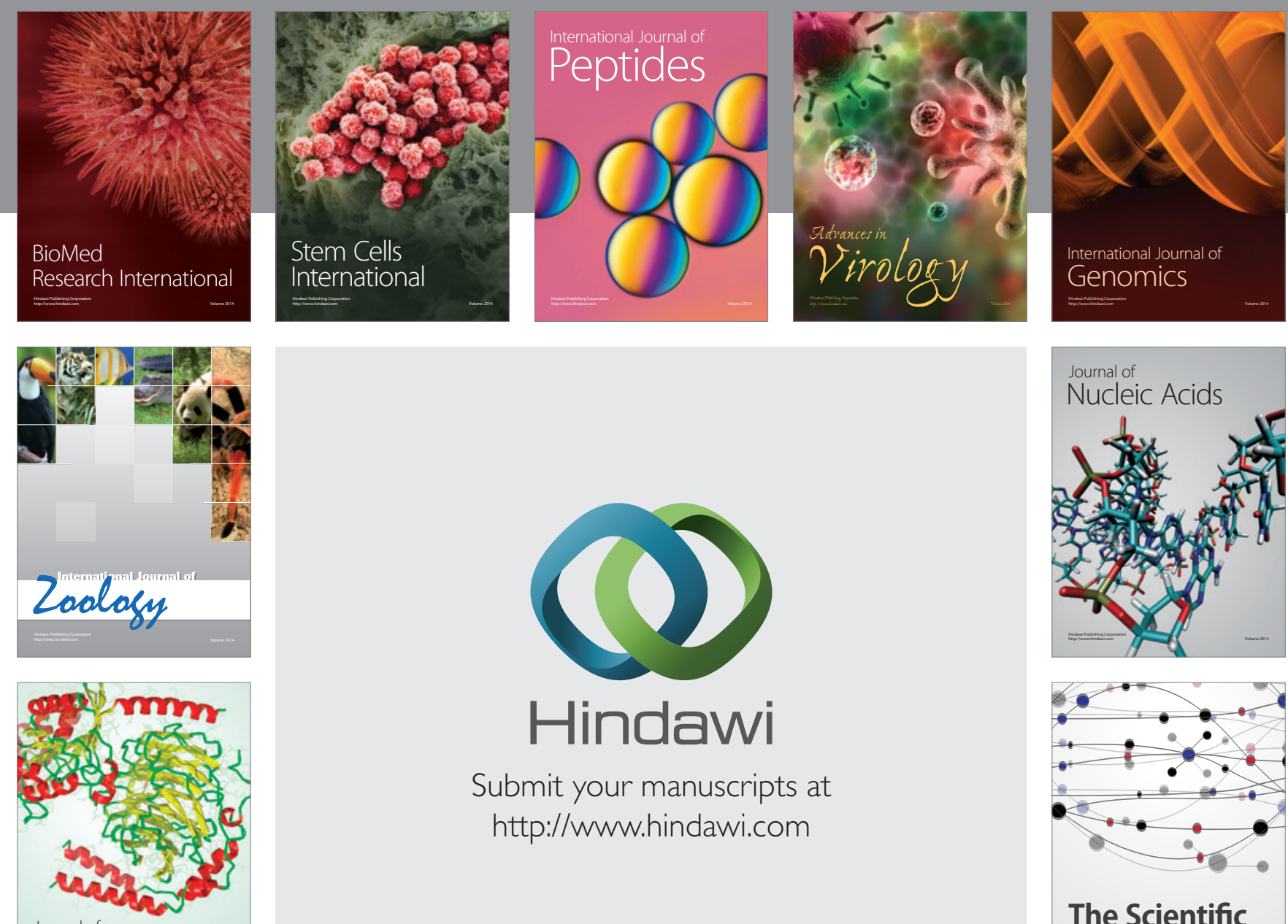

Submit your manuscripts at

http://www.hindawi.com

Journal of
Signal Transduction
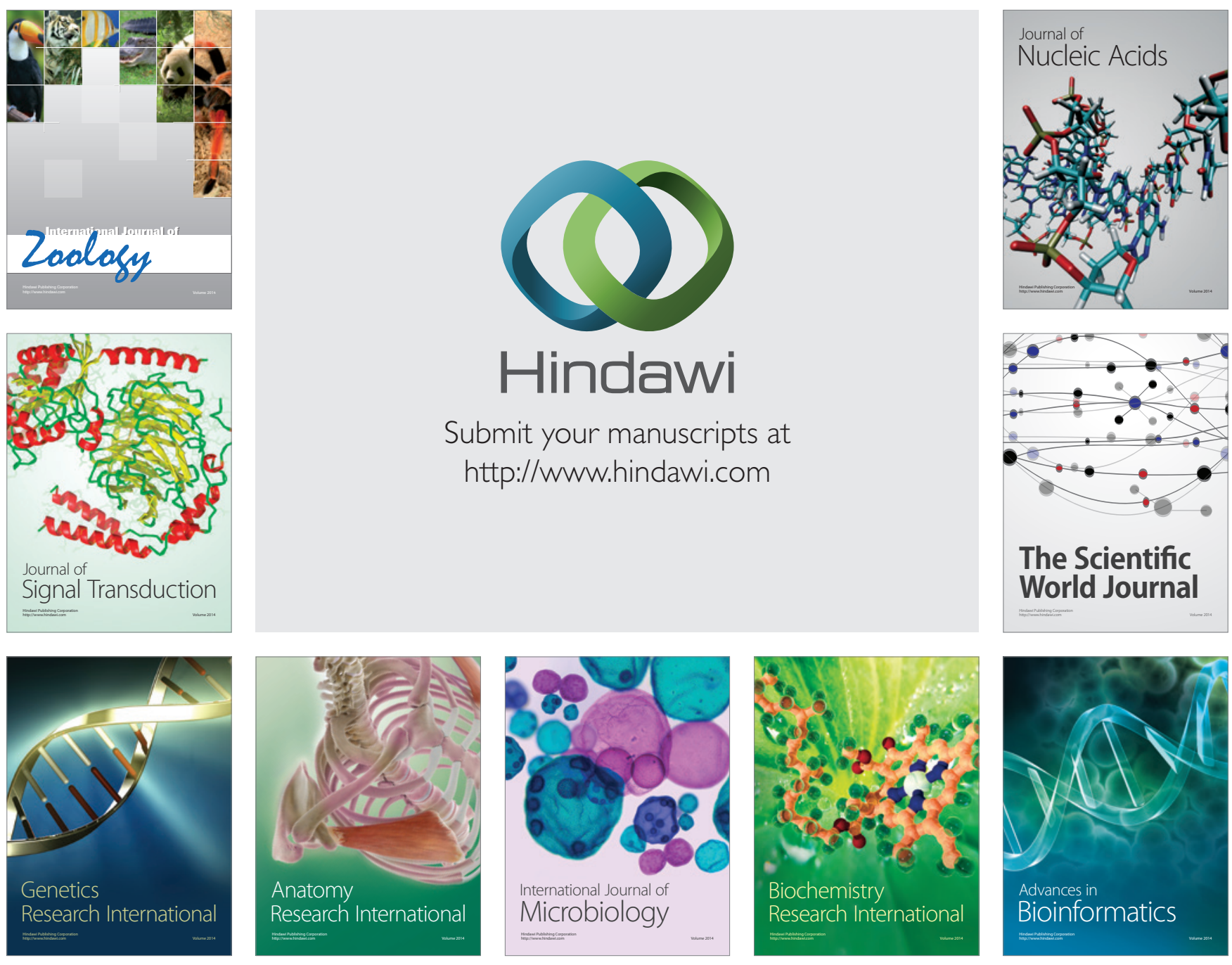

The Scientific World Journal
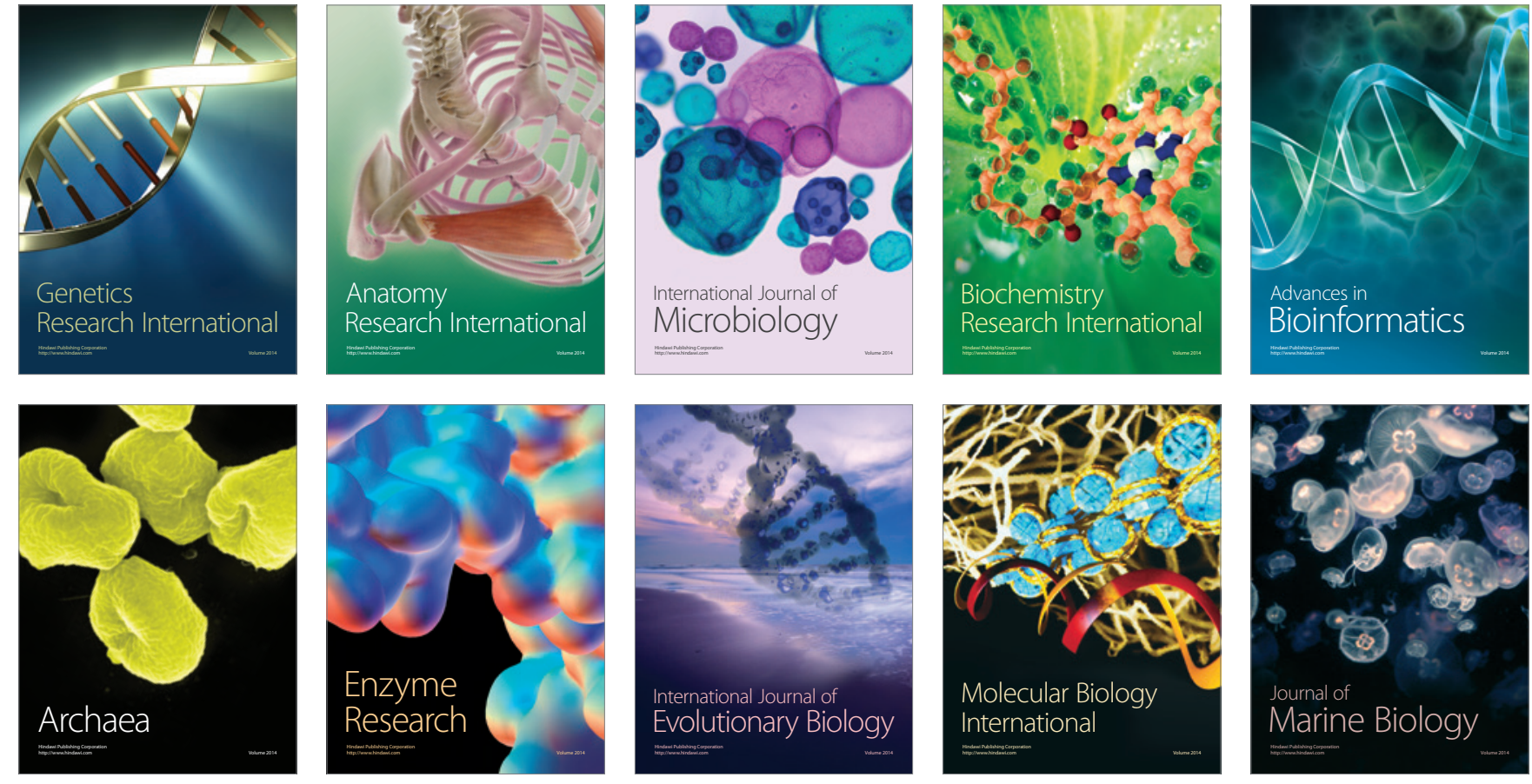